\title{
REVISTAMARACANAN
}

Dossiê

\section{A Sociedade Auxiliadora da Indústria Nacional e as patentes de invenção: tecnologia e propriedade no Império do Brasil}

\author{
The "Sociedade Auxiliadora da Indústria Nacional" and invention patents: \\ technology and property in the Empire of Brazil
}

\section{Leandro Miranda Malavota*}

Instituto Brasileiro de Geografia e Estatística Rio de Janeiro, Rio de Janeiro, Brasil

Recebido em: 12 set. 2019.

Aprovado em: 13 dez. 2019.

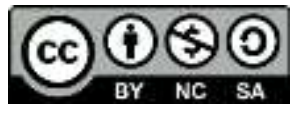

\footnotetext{
* Analista do Instituto Brasileiro de Geografia e Estatística - IBGE. Professor do Programa de Pósgraduação em Propriedade Intelectual e Inovação do Instituto Nacional da Propriedade Industrial - INPI. Doutor em História pela Universidade Federal Fluminense; Mestre em História Social pela Universidade Federal do Rio de Janeiro; e graduado em História pela Universidade Federal do Rio de Janeiro. (malavota@gmail.com) 


\title{
Resumo
}

Propomo-nos, no presente artigo, a investigar alguns aspectos relativos à atuação da Sociedade Auxiliadora da Indústria Nacional (SAIN) no fomento à atividade inventiva durante o terceiro quartel do século XIX. Nosso enfoque recai sobre o papel exercido pela instituição no processo de concessão de patentes a inventores e introdutores de novos bens e técnicas de produção. Partimos da análise da participação das seções temáticas da SAIN na avaliação da conveniência da concessão de exclusivos e da adequação dos pedidos de patentes às exigências legais, em atendimento a consultas do governo. Em meio a essa reflexão, são examinados os fundamentos técnicos, jurídicos e econômicos que sustentavam a atuação da SAIN, considerando-se a importância auferida pela tecnologia enquanto fator de produção no contexto da Segunda Revolução Industrial. Nesse sentido, conceituamos a instituição como um locus de organização dos interesses de frações da classe dominante, uma corporação intelectual voltada à racionalização e modernização das atividades produtivas no país.

Palavras-chave: Sociedade Auxiliadora da Indústria Nacional (SAIN). Sistema de patentes. Propriedade industrial. Privilégios de invenção. Brasil Império.

\begin{abstract}
This paper investigates the Sociedade Auxiliadora da Indústria Nacional's (SAIN) support of inventive activity during the third quarter of 19th century, with a focus on the institution's role in the evaluation of patents for inventors and introducers of new goods and technologies. We begin begin with an analysis of the participation of SAIN thematic sections in patent grant procedures, in consultation wtih the government. The technical, legal and economic foundations that underpin SAIN's operations are examined, considering the importance gained by technology as a factor of production in the context of the Second Industrial Revolution. In this sense, we conceptualize the institution as a locus of interests organized on behalf of the ruling class and its factions, and as an intellectual association focused on the rationalization and modernization of productive activities in the Empire of Brazil.
\end{abstract}

Keywords: Sociedade Auxiliadora da Indústria Nacional (SAIN). Patent System. Industrial Property. Privileges of Invention. Empire of Brazil. 


\section{Notas introdutórias}

Sob os auspícios do Imperador D. Pedro I, foi criada, em 1825, a Sociedade Auxiliadora da Indústria Nacional (SAIN), concebida como uma associação civil de assistência aos produtores nacionais e de fomento às chamadas artes úteis. Seus trabalhos foram inaugurados, de fato, em 1827, consumando os esforços despendidos durante mais de dez anos por seu grande idealizador, Ignácio Álvares Pinto de Almeida, homem de negócios da praça do Rio de Janeiro e Deputado da Junta do Comércio, Agricultura, Fábricas e Navegação. ${ }^{1}$ Sua missão principal era promover a racionalização, mecanização e aprimoramento das atividades produtivas do país - particularmente a agricultura, carro-chefe da economia - , 0 que envolvia a execução de ações de distintas naturezas: suporte e orientação aos produtores; divulgação científico-tecnológica; disseminação do conhecimento técnico pelos mais variados meios, incluindo o ensino profissionalizante. Interessam sobretudo à nossa investigação as iniciativas voltadas à oferta de incentivos e recompensas a "homens industriosos", tendo em vista o desenvolvimento da atividade inventiva e o aperfeiçoamento contínuo dos meios e processos de produção.

Não obstante a natureza jurídica privada da entidade, seus laços com o governo mostravam-se bastante estreitos. A SAIN recebia subvenções anuais do Tesouro, que se uniam aos recursos levantados pelos sócios efetivos - joias e mensalidades - e às assinaturas do periódico o Auxiliador da Indústria Nacional, publicado a partir de 1833. Além de suprir os cofres da instituição, o governo exercia controle sobre seus estatutos. A entidade também era subordinada à jurisdição de um órgão ministerial - inicialmente a Secretaria dos Negócios do Império e depois, a partir de 1860, a Secretaria dos Negócios da Agricultura, Comércio e Obras Públicas. Cabe ainda ressaltar que a SAIN constituiu um espaço frequentado, durante a maior parte de sua existência, por grandes personalidades do Império, ou, nas palavras do historiador José Luiz Werneck da Silva, "notabilidades palacianas", "capacidades políticas" e "sumidades intelectuais", membros da elite política nacional e integrantes da aparelhagem burocrática do Estado Imperial. ${ }^{2}$

A despeito de sua relevância como instância organizada da sociedade civil, os estudos históricos dedicados à SAIN não são muito abundantes. Werneck da Silva assinala que mesmo em obras clássicas que discutiram a organização política e econômica do Brasil Império as menções e considerações feitas em relação à SAIN foram exíguas, quando não absolutamente

\footnotetext{
${ }^{1}$ Natural da Bahia, Ignácio Álvares Pinto de Almeida era fabricante e negociante de aguardentes e outros destilados. Além do cargo de Deputado da Junta do Comércio e do comando da Secretaria daquele tribunal, ostentava ainda os títulos de Guarda-Roupa da Casa Imperial, Fidalgo Cavaleiro da Casa Real, Comendador da Ordem de Cristo e Cavaleiro da Ordem de Nossa Senhora da Conceição. Ver: BLAKE, A. V. S. Diccionario Bibliographico Brazileiro. Vol. 3. Rio de Janeiro: Imprensa Nacional, 1895, p. 260.

2 SILVA, J. L. W. Isto é o que me parece: a Sociedade Auxiliadora da Indústria Nacional (1827-1904) na formação social brasileira. 1979. Dissertação (Mestrado em História) - Instituto de Ciências Humanas e Filosofia, Universidade Federal Fluminense, Niterói (RJ), v. 1, p. 86-7.
} 
ausentes. ${ }^{3}$ De fato, sua dissertação de mestrado, defendida em 1979, constitui a primeira pesquisa de fôlego a eleger a Auxiliadora como objeto privilegiado. Alicerçado em uma extensa gama de fontes primárias, o autor se debruça sobre o ordenamento e funcionamento da SAIN, classificando-a como uma agência do campo intelectual cooptada pelo Estado monárquico, isto é, uma instituição que atuava na confluência entre o público e o privado, efetuando, em favor dos interesses da classe dominante, uma "mediação entre a superestrutura ideológica e a estrutura econômica". ${ }^{4}$ Suas funções, portanto, passavam tanto pela construção de elementos simbólicos que contribuíam para a construção e reforço da hegemonia dos segmentos de classe por ela representados, partícipes do bloco do poder, quanto de bens materiais que permitiam a expansão e a modernização das forças produtivas.

Ainda que não propriamente dedicadas à história da SAIN, algumas pesquisas produzidas também nos anos 1970 contribuíram para o aprofundamento das reflexões sobre a sua atuação. Edgar Carone, em trabalho sobre o Centro Industrial do Rio de Janeiro, classificou a Auxiliadora como uma instituição fortemente influenciada por um ideário ilustrado, dedicada à renovação e dinamização das atividades econômicas, prioritariamente a agricultura. ${ }^{5}$ Ponderou, entretanto, que a despeito da clareza de suas propostas e do voluntarismo de suas ações, configurou-se em sua trajetória um fosso entre a intenção e a realização, causado pelas próprias limitações do sistema escravista. Nesse sentido, as ações modernizadoras promovidas pela SAIN teriam gerado poucos efeitos na prática. Já em uma linha interpretativa oposta, Erdna Perugine identifica a SAIN como uma sociedade tipicamente científica, a única a se consolidar entre as congêneres criadas no Brasil no primeiro terço do Oitocentos, obtendo sucesso em sua missão de preencher a lacuna existente entre a ciência e a produção, a teoria e a prática. ${ }^{6}$

Em seu célebre estudo sobre a estrutura política e social do Império, José Murilo de Carvalho dedicou rápidas considerações à Auxiliadora. ${ }^{7}$ Em sua visão, a SAIN não constituiu propriamente um organismo de natureza política, apresentando feições muito mais técnicocientíficas. Não lhe parece que a instituição tenha demonstrado poder de ação ou pressão a

\footnotetext{
${ }^{3}$ SILVA, J. L. W. Isto é o... Op. cit., v. 2, p. 11-15. O autor se refere particularmente às seguintes obras: CALMON, P. História de Dom Pedro II. Tomo II: Cultura e Política, Paz e Guerra (1853-1870). Rio de Janeiro; Brasília: José Olympio; INL, 1975; VIANNA, H. Estudos de história imperial. São Paulo: Cia. Ed. Nacional, 1950; HOLLANDA, S. B. História Geral da Civilização Brasileira. Tomo II: O Brasil Monárquico. Vol. 5: Reações e Transações. São Paulo: DIFEL, 1972; URICOECHEA, F. O minotauro imperial: a burocratização do Estado Patrimonial Brasileiro no século XIX. São Paulo: DIFEL, 1978.

${ }^{4}$ SILVA, J. L. W. Isto é o... Op. cit., v.2, p. 25.

${ }^{5}$ CARONE, E. O Centro Industrial do Rio de Janeiro e sua importante participação na economia nacional (1827-1977). Rio de Janeiro: CIRJ; Cátedra, 1978, p. 13-68. Conforme aponta o autor, em 1904 a SAIN foi fundida ao Centro Industrial de Fiação e Tecelagem de Algodão, dando origem ao Centro Industrial do Brasil. Este foi transformado na Federação das Indústrias do Rio de Janeiro, em 1931, e dez anos depois adotou o nome de Centro Industrial do Rio de Janeiro (CIRJ).
}

6 PERUGINE, E. Palavra indústria na revista O Auxiliador da Indústria Nacional: 1833-1843. 1978. Dissertação (Mestrado em História Social) - Faculdade de Filosofia, Letras e Ciências Humanas, Universidade de São Paulo, São Paulo, 1978, p. 162-3.

7 CARVALHO, J. M. A construção da ordem: a elite imperial. Teatro das sombras: a política imperial. $3^{a}$ ed. Rio de Janeiro: Civilização Brasileira, 2007. 
ponto de provocar a adoção de medidas concretas em favor do desenvolvimento da lavoura ou dos demais ramos da economia. Em sua visão, "a Sociedade era algo mais próximo de um centro de estudos ou sociedade literária", ${ }^{8}$ sendo a atuação de seus membros "muito mais simbólica e honorífica do que instrumental". ${ }^{9}$ Embora reconheça que os trabalhos desenvolvidos pela SAIN tenham eventualmente servido a projetos reformistas, Carvalho não concebe a instituição como um dos principais espaços para a representação política dentro da ordem imperial.

A ênfase ao caráter predominantemente científico da SAIN é reforçada por estudos posteriores, estes, sim, propriamente focados na instituição. Para Heloísa Bertol Domingues, a Auxiliadora foi uma das mais importantes associações científicas surgidas no contexto pósindependência, propondo-se a apoiar o governo na implementação de ações e políticas voltadas ao avanço do conhecimento científico e sua aplicação à produção. ${ }^{10} \mathrm{Em}$ seu entendimento, a SAIN pode ser tomada como uma peça importante do processo de institucionalização das ciências no Brasil, uma associação que, embora criada sob a égide, o apoio e o controle do Estado, não se propunha a ser mera porta-voz do poder, mantendo em relação ao governo relativa autonomia, atuando em seu auxílio em razão de interesses convergentes. Seguindo linha análoga, Priscila Regina Barreto afirma que a Auxiliadora é resultado do espírito da ilustração, constituindo uma comunidade científica alargada, congregando técnicos, intelectuais, políticos e homens de negócio. ${ }^{11}$ Define então a SAIN com um espaço fundamental para a construção de uma tradição científica e para o desenvolvimento de uma ciência aplicada no país.

Por ter constituído um importante foro de debate sobre os principais temas que compunham a agenda político-econômica do Império e produzido abundantes registros sobre as suas atividades, a SAIN oferece ao historiador uma porta de entrada para o enfrentamento de questões diversas relacionadas ao Oitocentos brasileiro, tais como a extinção do trabalho escravo, imigração, protecionismo alfandegário, expansão da cafeicultura, industrialização, divulgação científica, ensino, entre outras. Chamam particularmente a nossa atenção aquelas relacionadas à concessão de patentes a inventores, seara infelizmente ainda pouco explorada. Werneck da Silva teceu algumas considerações sobre o assunto em sua obra pioneira, descrevendo os trabalhos desempenhados pelas seções temáticas e analisando reflexões e críticas concernentes à Lei de Patentes de 1830. ${ }^{12}$ Luiz Cláudio Moisés Ribeiro, por sua vez, utilizou os pedidos de patentes encaminhados à SAIN e os pareceres produzidos por suas

\footnotetext{
${ }^{8}$ CARVALHO, J. M. A construção da ordem... Op. cit., p. 52. Grifos do autor.

${ }^{9}$ Idem.

${ }^{10}$ DOMINGUES, H. M. B. A Sociedade Auxiliadora da Indústria Nacional e as Ciências Naturais no Brasil Império. In: DANTES, M. A. M. (org.) Espaços da Ciência no Brasil: 1800-1930. Rio de Janeiro: Ed. Fiocruz, 2001, p. 83-112.

${ }^{11}$ BARRETO, P. R. C. Sociedade Auxiliadora da Indústria Nacional: o templo carioca de Palas Atena. 2009. Tese (Doutorado em História das Ciências e das Técnicas e Epistemologia) - Universidade Federal do Rio de Janeiro, Rio de Janeiro.
}

${ }^{12}$ SILVA, J. L. W. Isto é o... Op. cit., v.1, p. 178-183. Ibidem, v.2, p. 101-102. 
seções especializadas - além de várias outras fontes - para analisar os inventos e aprimoramentos desenvolvidos no setor cafeeiro entre 1873 e 1910, chamando a atenção para a formação de um setor produtor de máquinas e equipamentos agrícolas no país. ${ }^{13}$ Em pesquisa mais recente, João Carlos Vanucci lança mão do conteúdo publicado em $O$ Auxiliador para avaliar a contribuição da SAIN no processo de concessão de privilégios a inventores e introdutores, enfatizando seus aspectos propriamente tecnológicos. ${ }^{14} \mathrm{O}$ autor descreve algumas dezenas de pedidos encaminhados à SAIN entre 1833 e 1862 e examina, a partir desses processos, a evolução tecnológica ocorrida em segmentos produtivos específicos, com destaque para as culturas canavieira e cafeeira.

Propomo-nos neste trabalho a prestar uma contribuição aos ainda incipientes estudos sobre inovação e patentes no Brasil do século XIX. Partindo de um exame das funções cumpridas pela entidade e do papel por ela cumprido como espaço de reflexão sobre as ciências e as artes úteis, buscaremos identificar, primeiramente, algumas das contribuições prestadas pela SAIN como instância de assessoramento ao governo, através da apreciação dos pedidos de patentes encaminhados por inventores. Trataremos posteriormente das razões e interesses envolvidos nas intervenções e posicionamentos institucionais, considerando a SAIN como uma entidade de representação de segmentos da classe dominante, em um contexto no qual a importância da tecnologia como fator de produção se consolidava. Para o desenvolvimento de nossa investigação, tomaremos como fontes os estatutos da instituição, os registros das reuniões de seu Conselho Administrativo e das seções especializadas, bem como artigos, memórias e relatórios publicados em O Auxiliador da Indústria Nacional.

\section{A SAIN e as patentes}

Concluída em 1808, no contexto das guerras napoleônicas, a transladação da Corte portuguesa para o Brasil provocou medidas voltadas à superação dos estatutos coloniais aos quais a economia local estava submetida. Para além da abertura dos portos e da decretação da liberdade de indústria, ${ }^{15}$ são dignas de nota as providências tomadas por meio do Alvará do Príncipe Regente de 28 de abril de 1809, ato que estabeleceu estímulos à instalação de fábricas e à construção naval. Entre os mecanismos nele previstos englobavam-se isenções fiscais, políticas de compras governamentais, financiamentos diretos à produção e ferramentas

13 RIBEIRO, L. C. M. Ofício criador: invento e patente de máquina de beneficiar café no Brasil (18701910). 1995. Dissertação (Mestrado em História) - Faculdade de Filosofia, Letras e Ciências Humanas, Universidade de São Paulo, São Paulo.

14 VANUCCI, J. C. P. As invenções técnicas brasileiras no Segundo Reinado. Estudo das Comissões Técnicas da Sociedade Auxiliadora da Indústria Nacional nas concessões de privilégios de patentes entre 1833 e 1862. 2016. Tese (Doutorado em História da Ciência) - Pontifícia Universidade Católica, São Paulo.

15 A derrubada do exclusivo dos comerciantes portugueses e a consequente legalização do comércio direto entre a colônia e as "nações amigas" foram decretadas por Carta Régia datada de 28 de janeiro de 1808. Já a anulação das restrições legais ao desenvolvimento de atividades fabris no Brasil foi determinada pelo Alvará de $1^{\circ}$ de abril daquele mesmo ano. 
de fomento à incorporação de novas máquinas e técnicas à produção. Quanto a estas últimas, estabelecia o Alvará, em seu parágrafo VI, a regulamentação da prática - já há muito consagrada em Portugal e suas colônias - de concessão de exclusivos a inventores e introdutores. ${ }^{16}$ O referido diploma, portanto, constituiu a primeira legislação patentária promulgada pelo Estado português, estabelecendo os procedimentos necessários para a solicitação de patentes, requisitos para concessão, bem como prazos, aplicações e objetivos dos exclusivos. ${ }^{17}$

A despeito de ter sido promulgado em um quadro de ocupação da metrópole por uma nação estrangeira, o estatuto joanino era aplicável a todas as possessões portuguesas. No caso do Brasil, os pedidos deveriam ser encaminhados e examinados pela recém-criada Real Junta de Comércio, Agricultura, Fábricas e Navegação do Estado do Brasil e seus Domínios Ultramarinos. ${ }^{18}$ Erigida à imagem e semelhança de sua congênere lisboeta, como parte do processo de reprodução da aparelhagem burocrática do Estado português na nova capital do Império, constituiu-se igualmente como Tribunal Superior, funcionando como instância de coordenação, regulação e apoio aos setores produtivos. Deve-se ressaltar, entretanto, que as concessões de patentes a inventores, assim com antes da promulgação do Alvará, permaneciam em última instância como prerrogativa régia.

A emancipação política do Brasil não alterou o arcabouço jurídico-institucional de incentivo à atividade inventiva, permanecendo a Junta do Comércio do Rio de Janeiro como instância de apreciação dos pedidos e o Alvará joanino de 1809 como principal marco regulatório. Somente em 1830 seria promulgada uma nova legislação, que provocou poucas mudanças no modelo vigente havia duas décadas. ${ }^{19}$ Porém, se o Alvará de 1809 estabelecia explicitamente a Junta do Comércio como instância responsável pela apreciação dos pedidos de privilégio, no novo diploma o mesmo não ocorria. Abriu-se com isso oportunidade para que outros agentes e agências, públicos e privados, fossem chamados a opinar sobre a legalidade e conveniência das concessões.

Já o seu primeiro estatuto - aprovado em 1825 e vigente até 1831 - atribuía à SAIN a obrigação de prestar todo o favor possível a pessoas que quisessem importar máquinas ou modelos para seu uso, oferecer estímulos e recompensas em benefício da indústria, bem como avaliar, chancelar e divulgar memórias sobre modelos e inventos. ${ }^{20} \mathrm{Em}$ função da natureza

\footnotetext{
16 Definimos como "introdução" a difusão de bens e processos já conhecidos no exterior, porém ainda inéditos em um dado domínio territorial.

17 MALAVOTA, L. M. A construção do sistema de patentes no Brasil: um olhar histórico. Rio de Janeiro: Lumen Juris, 2011, p. 47-55.

${ }^{18}$ A Real Junta do Comércio do Rio de Janeiro foi criada por meio do Alvará com força de lei de 23 de agosto de 1808.

${ }^{19}$ Lei $\mathrm{s} / \mathrm{n}^{\circ}$ de 28 de agosto de 1830.

${ }^{20}$ Estatutos da Sociedade Auxiliadora da Indústria Nacional. Rio de Janeiro: Typographia Imperial, 1828. Cabe ressaltar que o termo "indústria", nesse contexto, tinha uma aplicação bastante ampla, podendo ser entendido tanto como reunião de atividades mecanizadas quanto como qualquer ação engenhosa geradora de riqueza. Assim, para muito além da concepção de fábrica ou manufatura, a terminologia era empregada para qualquer laboração com algum grau de complexidade ou que exigisse habilidade específica, incluindo a agricultura, o comércio e o artesanato.
} 
dessas atividades, logo demandou o governo, por meio de consultas, o suporte da Auxiliadora para o cumprimento de determinadas funções. Entre elas, o exame dos pedidos de patentes efetuados por inventores e introdutores. A Lei de Patentes de 1830 estabelecia critérios e requisitos para a concessão de exclusivos a inventores, sendo a aferição do enquadramento dos pleitos aos dispositivos legais executada por meio de um exame prévio. A Secretaria dos Negócios do Império, exercendo um poder delegado pelo Imperador, era a instância incumbida de efetuar as concessões, contando - por determinação da própria lei - com o auxílio do Procurador da Coroa, Fazenda e Soberania Nacional. Ao contrário do marco regulatório que a precedeu, a nova legislação determinava somente que os pedidos de privilégio deveriam ser encaminhados ao Arquivo Público, sem mencionar uma instância responsável pelo exame do pedido. De tal modo, a Secretaria dos Negócios do Império e o Procurador da Coroa poderiam lançar mão dos auxílios que considerassem necessários. Como ocorria desde 1809, o Tribunal da Junta do Comércio continuou a ser acionado. Em meados da década de 1840, o Conselho de Estado - ou mais especificamente, a sua Seção dos Negócios do Império - também passou a se pronunciar sobre a conveniência e legalidade das concessões, amparando as decisões régias. E é justamente nesse contexto que ganha notoriedade a SAIN, sendo chamada a se tornar uma dessas instituições intervenientes, dando suporte, a partir da expertise de seus sócios, às decisões governamentais.

Com a primeira revisão de seus estatutos em 1831, foram constituídas na SAIN comissões especializadas encarregadas do tratamento de assuntos relativos aos seus campos de atuação. Originalmente, eram seis essas comissões: Fundos; Análises e Processos Químicos; Economia Rural e Doméstica; Agricultura; Artes, Fábricas e Comércio; Programas, Redação de Jornais e Revisão de Memórias. ${ }^{21}$ Uma vez recebidas pelo Conselho Administrativo, ${ }^{22}$ eram as consultas preliminarmente analisadas e então remetidas, de acordo com as áreas de aplicação dos objetos examinados, a essas comissões, cada uma delas composta por três sócios efetivos. Em seu âmbito eram elaborados pareceres, que por sua vez eram posteriormente apreciados e votados em sessões do Conselho Administrativo. Se aprovados, eram remetidos à instância ou autoridade responsável pela consulta, expressando o posicionamento oficial da instituição.

Identificamos a primeira experiência da SAIN no campo das patentes em um processo iniciado em 1833, resultado de uma consulta encaminhada pela Regência, em nome do Imperador, por meio de Portaria do Ministério do Império datada de 25 de outubro. Solicitava-

\footnotetext{
${ }^{21}$ Estatutos da Sociedade Auxiliadora da Indústria Nacional, novamente organizados em conformidade da provisão de 31 de outubro de 1825, e do aviso de 5 de agosto de 1831. Rio de Janeiro: Typographia Austral, 1838. A configuração dessas comissões (criadas em 1831 como "Comissões Permanentes" e mais tarde sendo designadas como "Seções") variou ao longo do tempo. A divisão temática supracitada, por exemplo, perdurou somente até 1848 , sendo totalmente reorganizada por efeito de uma nova revisão estatutária.

22 O Conselho Administrativo da SAIN era composto pelos membros da diretoria (presidente, vicepresidente, secretário e tesoureiro) e das comissões. Seus integrantes eram eleitos pela Assembleia Geral da entidade, exercendo mandato de um ano, com exceção do secretário, cuja cadeira era perpétua. A nomeação dos membros do Conselho Administrativo era condicionada a aprovação imperial.
} 
se o pronunciamento da instituição quanto à melhor forma de recompensa a ser concedida a Antônio de Santo Valério Scheult, inventor de uma "máquina de vaso aberto tendente a transformar o sumo da cana em açúcar de 70 a 80 graus do termômetro centígrado, sem produção de melaço". ${ }^{23}$ A consulta foi encaminhada à apreciação de uma comissão especial composta pelos membros de duas de suas comissões permanentes - Agricultura e Análises e Processos Químicos - e por mais três outros sócios efetivos convidados, todos proprietários de engenhos. Naquela ocasião, o parecer das comissões reunidas apontou que, checados os requisitos de patenteabilidade, a invenção se mostrava digna de receber o privilégio. Porém, dados os benefícios que o maquinismo poderia proporcionar à produção nacional de açúcar, recomendava-se ao governo a promoção de sua imediata vulgarização, pagando-se em troca, como recompensa ao inventor pela revelação do seu segredo, uma quantia de sessenta contos de réis. Tratava-se, portanto, da aplicação do artigo $6^{\circ}$ da Lei de Patentes de 1830, que previa a "compra" da propriedade do inventor em casos de notório interesse público. O Ministério do Império, no entanto, considerou elevada a quantia proposta e as negociações entre as partes não evoluíram. As recomendações da SAIN, nesse caso, acabaram não sendo aplicadas pelo governo.

Foram escassas as consultas encaminhadas à SAIN nas décadas de 1830 e 1840 , posto que o argumento de autoridade sobre a matéria ainda pertencia à Junta do Comércio. Somente com a definitiva dissolução do Velho Tribunal, em 1850, a Auxiliadora passaria a ser mais acionada. A pesquisa desenvolvida por João Carlos Vanucci identificou um total de 62 consultas entre 1833 e 1862, sendo 58 delas após a extinção da Junta do Comércio. ${ }^{24}$ Considerando ainda que a partir de 1842 os pedidos de privilégio também começaram a passar pelo crivo da Seção dos Negócios do Império do Conselho de Estado, e que até 1861 foram gerados em seu âmbito 134 processos, podemos estimar que em cerca de $45 \%$ dos pedidos de patentes a opinião da SAIN foi ouvida. ${ }^{25}$

No início dos anos 1860, o gabinete conservador presidido por Ângelo Moniz da Silva Ferraz, Barão de Uruguaiana, promoveu uma reforma na aparelhagem administrativa de primeiro escalão, consubstanciada na criação da Secretaria dos Negócios da Agricultura, Comércio e Obras Públicas. O novo ministério absorveu parte das atribuições da Secretaria dos Negócios do Império e sob sua responsabilidade ficaram todos os assuntos ligados à promoção e regulação das atividades econômicas. A um de seus órgãos de direção superior, a Diretoria

${ }^{23}$ O Auxiliador da Indústria Nacional, Rio de Janeiro, ano II, n. 3, fev. 1834, p. 65-87. Doravante identificado como $O$ Auxiliador.

${ }^{24}$ VANUCCI, J. C. P. As invenções técnicas brasileiras... Op. cit., p. 44.

25 Os processos envolvendo pedidos de patentes remetidos à Seção dos Negócios do Império do Conselho de Estado podem ser encontrados no Arquivo Nacional do Rio de Janeiro (AN-RJ), Fundo do Conselho de Estado, códice 276, volumes 1 a 5 . Contabilizamos somente as respostas a consultas acerca de pedidos de privilégios enquadrados aos dispositivos da Lei de 28 de agosto de 1830, excluindo os demais (navegação, mineração, serviços públicos em geral ou indústrias vulgares). Identificamos no interstício 1842-1861 um total de 134 pedidos, tendo 99 deles deferidos. Lembramos que a concessão de patentes era uma prerrogativa do Imperador, servindo o parecer da Seção dos Negócios do Império como suporte para a decisão do monarca. Observamos, contudo, que a todos os deferimentos seguiu o "como parece" do Imperador. 
Central e dos Negócios da Agricultura, Comércio e Indústria, recaiu a incumbência da "concessão de patentes pela invenção e melhoramento de indústria útil, e a de prêmios pela introdução de indústria estrangeira". ${ }^{26}$ Também sob a sua jurisdição foi colocada a SAIN, cuja função consultiva na apreciação dos pleitos de privilégios patentários foi mantida.

Podemos afirmar que no par de décadas que se seguiram os exames das invenções passaram a compor o grosso das atividades desempenhadas pelas seções especializadas da SAIN. No que concerne ao trâmite burocrático, os procedimentos permaneceram os mesmos, exceto quanto ao número de sessões especializadas, àquela altura já bastante alargado. ${ }^{27}$ As respostas às consultas, no entanto, passavam a ser encaminhadas à Diretoria Central do ministério, para posterior sanção do Imperador. Na dimensão substantiva dos exames, isto é, a aplicação de critérios para o patenteamento e a interpretação das normas legais, nota-se também uma relativa regularidade ao longo do tempo. O conceito da novidade (ineditismo da invenção) constituía o critério determinante para a recomendação de concessão de um privilégio. Citamos o caso do pedido feito em 1875, por José de Faria Loureiro Coimbra, para uso exclusivo de um tipo de carroça para transporte de trastes. ${ }^{28}$ Pronunciando-se sobre o pleito, a Seção de Comércio e Meios de Transporte emitiu seu parecer nos seguintes termos:

Atendeu a Secção ao que foi exposto pelo peticionário, e minuciosamente estudou os desenhos apresentados, e chegou à convicção de que não há invenção alguma, própria do suplicante nas carroças que projeta, e que as molas de que fala em sua memória descritiva existem aplicadas em outros veículos muito usados nesta e outras cidades. Não ha também introdução de indústria nova.

Nada embaraça ao suplicante o poder continuar a ocupar-se da condução de trastes nos seus antigos ou novos veículos em concorrência com quaisquer outros que já existem ou possam estabelecer-se com a mesma indústria.

Já não é esta a primeira informação que a secção dá a idênticas pretensões e não tem ainda motivo para opinar diferentemente.

Assim, pois, em conclusão: é de parecer a Secção, que o privilégio solicitado não tem razão de ser e como tal não está no caso de ser deferido. ${ }^{29}$

A comissão, portanto, interpretou a suposta invenção como um objeto vulgar, cuja patente seria deletéria ao interesse do público em geral. A defesa da liberdade de comércio mostrava-se como argumento a respaldar a recomendação de indeferimento, mas o que configurava a ofensa ao liberal princípio não era a eventual outorga do exclusivo para exploração de um dado bem, mas, o fato de este último constituir um objeto de uso comum no Império, não uma invenção ou introdução.

\footnotetext{
${ }^{26}$ Decreto n. ${ }^{0} 2.748$, de 16 de fevereiro de 1861.

27 De acordo com os estatutos modificados em 1869 (e válidos até 1891), essas seções passaram a se dividir em dez áreas: Agricultura; Indústria Fabril; Máquinas e Aparelhos; Artes Liberais e Mecânicas; Comércio e Meios de Transporte; Geologia Aplicada e Química Industrial; Zoologia; Estatística; Colonização e Estatística; Finanças da Sociedade. BRASIL. Decreto no 4.333, de 12 de fevereiro de 1869. Aprova a reforma dos estatutos da Sociedade Auxiliadora da Indústria Nacional. Coleção de Leis do Império do Brasil, tomo XXXII, parte II. Rio de Janeiro: Typographia Nacional, 1869, p. 40-47.
}

${ }^{28}$ O Auxiliador, Rio de Janeiro, ano XLV, n. 12, dez. 1875, p. 486-487.

${ }^{29}$ Ibidem, p. 487. 
Além da aferição da novidade, outra questão costumeiramente observada era a falsa reivindicação de autoria para inventos desconhecidos no Brasil. Nesses casos, os pareceristas costumavam ser bastante duros, não apenas denegando o privilégio, mas também condenando veementemente os falsos inventores. Um bom exemplo pode ser observado no parecer emitido em dezembro de 1870 pela Seção de Máquinas e Aparelhos, referente ao pedido de privilégio efetuado por Guilherme Telles Ribeiro para introduzir no Império o sistema de transporte funicular. No texto, além de se recomendar o indeferimento do pleito, exortava-se o governo sobre os riscos de se conceder privilégios aos que se apresentavam enganosamente como inventores. Além de constituir uma nítida infração ao direito de propriedade do verdadeiro inventor, ato passível de reprovação e censura, esses privilégios poderiam, segundo os membros da seção, "causar reclamações diplomáticas, ás quais não poder[ia] o Governo Imperial responder vitoriosamente fundado nos princípios imutáveis e universais de justiça e de moral". ${ }^{30}$

$\mathrm{Na}$ medida em que suas atividades se expandiam e que seu prestígio aumentava, a SAIN se consolidava como a principal referência em questões envolvendo a inovação e os direitos do inventor no país. Considerando o papel estratégico desempenhado pelas patentes em uma economia em rápida transformação, impactada pelos avanços tecnológicos ocorridos no contexto da chamada $2^{a}$ Revolução Industrial, ideias em evidência na Europa e nos Estados Unidos passavam a circular entre os membros da Auxiliadora, provocando debates acerca do funcionamento do arcabouço jurídico-institucional brasileiro. Além das considerações efetuadas no âmbito das seções especializadas, tornou-se também frequente a publicação de traduções e comentários sobre artigos produzidos por reconhecidos especialistas na matéria, no intuito de se oferecer subsídios às discussões sobre a experiência nacional. Um exemplo foi o artigo escrito em 1861 por Frederico Leopoldo César Burlamaqui, sócio efetivo da SAIN e então diretor do Museu Nacional, ${ }^{31}$ traduzindo e comentando um texto escrito por Jean Baptiste Jobard, publicista belga reconhecido como um dos maiores especialistas em patentes na Europa. ${ }^{32}$ Alicerçados principalmente na afirmação do direito inviolável de todo inventor de se apropriar dos frutos de seu próprio trabalho, Jobard tecia uma série de comentários que, na opinião do tradutor, poderiam ser facilmente associados aos dispositivos que compunham a Lei de Patentes de 1830. Primeiramente, Jobard se posicionava de maneira contrária ao exame prévio das invenções, procedimento adotado tanto na Bélgica, alvo de suas reflexões, quanto no Brasil, conforme ressaltava Burlamarqui. O procedimento era tomado como desnecessário e arbitrário, uma intervenção indevida do Estado sobre uma matéria de foro privado, além de tecnicamente imperfeito, posto que de difícil execução. Outro procedimento ao qual o autor se mostrava contrário era a possibilidade de compra da invenção pelo Estado como alternativa aos direitos de propriedade. Segundo Jobard, ambos os procedimentos - exames prévios e

\footnotetext{
30 O Auxiliador, Rio de Janeiro, ano XXXVIII, n. 1, jan. 1871, p. 72.

31 Além de sócio efetivo da SAIN, Burlamaqui era também membro da Academia Nacional de Belas Artes, do Instituto Histórico e Geográfico Brasileiro e de outras sociedades científicas e literárias no exterior.
}

${ }^{32}$ O Auxiliador, Rio de Janeiro, ano XXXII, n. 4, abr. 1861, p. 133-150. 
"compra do segredo" - seriam indesejáveis tanto pela possibilidade de abusos por parte de autoridades estatais quanto pela subjetividade dos critérios adotados para medir o mérito, a utilidade e o valor de uma dada invenção. Para ele, somente o mercado, através de seus livres mecanismos e forças, seria capaz de efetuar tal juízo. Declarava-se, por último, favorável ao que denominava como "patentes de introdução", ou seja, a concessão de direitos de exclusão a introdutores de atividades industriais já conhecidas no estrangeiro, porém não exploradas em territorial nacional. Aquelas eram tomadas como instrumentos justos e eficientes para atração de investimentos externos, importantes para economias menos avançadas.

Como contraponto às ideias expostas e defendidas por Burlamarqui, encontramos um artigo anônimo publicado em agosto de 1881, também voltado ao tema da propriedade industrial. ${ }^{33}$ Toda a argumentação do articulista é baseada na obra do economista francês Michel Chevalier, ferrenho crítico do sistema de patentes e de seus efeitos sobre a atividade econômica. O texto põe em dúvida a importância das patentes enquanto instrumentos eficientes para o avanço da tecnologia e da atividade produtiva, sob alegação de que o desejo de lucro imediato e fácil faz com que inúmeras pessoas se lancem em uma louca corrida em busca de monopólios, pouco importando o mérito das invenções desenvolvidas nem os benefícios por ela proporcionados à sociedade. Argumentava o autor que em todo o mundo proliferavam pedidos de exclusivos para objetos de baixo conteúdo tecnológico e pouca relevância, que, uma vez patenteados, conferiam lucros exorbitantes a quem os explorava, mas eram prejudiciais aos interesses dos consumidores, cujo acesso a esses bens era condicionado ao dispêndio de quantias elevadas. Além disso, alegava que patentes constituíam privilégios desnecessários, pois os verdadeiros homens de gênio, aqueles que dedicavam suas vidas à ciência e às artes, geralmente não se interessavam em requerer exclusivos, "contentando-se com a glória e as vantagens indiretas que oferecem à comunidade em que vivem". ${ }^{34} \mathrm{O}$ sistema patentário, enfim, era tomado como uma estrutura ofensiva à liberdade de comércio e trabalho, elevando os preços, inibindo a concorrência e obstaculizando o progresso da ciência e da indústria, uma vez que restringia o acesso do público a novas tecnologias. Por fim, o texto envereda para uma crítica explícita à Lei de Patentes de 1830, conceituando-a como "um tecido de contradições e ideias vagas". ${ }^{35}$

Esse ambiente propício à circulação de ideias e constante reflexão - aliado à autoridade técnica progressivamente auferida pela SAIN - contribuiu para a construção de propostas de alteração na legislação patentária. A primeira oportunidade ocorreu em 1861, quando após debate interno a instituição produziu um documento, logo encaminhado à Assembleia Geral Legislativa, com o intuito de servir como base para uma ampla revisão na Lei

\footnotetext{
33 O Auxiliador, Rio de Janeiro, ano XLIX, n. 8, ago. 1881, p. 175-177. Seção "Privilégios".

${ }^{34}$ Ibidem, p. 176.

${ }^{35}$ Ibidem, p. 177.
} 
de Patentes de $1830 .^{36}$ Essa representação da SAIN foi recebida pelo Parlamento e serviu como referência, oito anos depois, para a elaboração de um projeto de lei no âmbito da Câmara dos Deputados. ${ }^{37}$ No entanto, a iniciativa, que pretendia aproximar a legislação brasileira dos padrões adotados nas principais economias capitalistas, acabou não avançando no plenário. Em razão desse primeiro fracasso, nova proposta foi formulada pela SAIN em 1874, sendo desta vez elaborada uma minuta de lei, não apenas uma compilação de críticas e sugestões, como na experiência anterior. ${ }^{38} \mathrm{O}$ trabalho foi desenvolvido pelo então Secretário da entidade, José Pereira do Rego Filho, auxiliado por outro sócio efetivo, o engenheiro André Rebouças, presidente da Seção de Máquinas e Aparelhos. Inspirado na legislação norteamericana, o texto dispunha não somente sobre patentes, mas também sobre desenhos e modelos industriais, marcas de comércio, além dos direitos de cópia e reprodução de obras artísticas e literárias. Em meio a disposições distribuídas em 88 artigos, destacamos a proposta de criação de uma repartição ligada ao Ministério da Agricultura, Comércio e Obras Públicas chamada Diretoria Geral das Patentes de Invenção do Império do Brasil - responsável por serviços relativos aos privilégios (exame, concessões, anulações, prorrogações, resolução de litígios, etc.). Seu quadro técnico seria composto pelos membros das seções especializadas da SAIN e suas decisões só poderiam ser revistas pelo Conselho Administrativo da própria entidade, em recurso de primeira instância, ou pelo Supremo Tribunal de Justiça, em última instância. Previa-se também a transformação de $O$ Auxiliador em gazeta oficial da nova repartição pública. Percebemos, portanto, uma clara intenção de ampliar a autoridade da SAIN no campo patentário, extrapolando-se a dimensão consultiva e conferindo-lhe poder decisório.

Após aprovação no Conselho Administrativo, o projeto de Rego Filho foi encaminhado ao então ministro da Agricultura, Comércio e Obras Públicas, José Fernandes da Costa Pereira Júnior, em 20 de abril de 1874. Nenhum registro encontramos, nem nos anais das duas câmaras legislativas nem nos relatórios ministeriais, sobre o destino daquele material. Contudo, é certo que, assim como a Representação de 1861, a proposta de 1874 não gerou impactos sobre a legislação patentária. Para Werneck da Silva, o insucesso da primeira iniciativa pode estar relacionado ao momento político em que a mesma foi concebida, marcado por uma situação liberal. ${ }^{39}$ Segundo o autor, embora seu quadro de sócios contasse com representantes de ambos os grandes partidos que compunham o sistema político do Império, ${ }^{40}$

36 Representação dirigida pela Sociedade Auxiliadora da Indústria Nacional à Assembleia Geral Legislativa, pedindo a modificação de alguns artigos da Lei de 28 de agosto de 1830. O Auxiliador, Rio de Janeiro, ano XXIX, n. 8, ago. 1861, p. 288-301.

37 BRASIL. Câmara dos Deputados. Anais do Parlamento Brasileiro. Câmara dos Srs. Deputados. Primeiro ano. da décima quarta legislatura. Sessão de 1869. Tomo 5. Rio de Janeiro: Typographia Imperial e Constitucional de J. Villeneuve \& Co., 1869, p. 60-65.

38 Projeto de lei para privilégios de invenção no Império do Brasil. O Auxiliador, Rio de Janeiro, ano XLII, n. 5, maio 1874, p. 201-21. Em função de sua extensão, a reprodução do projeto teve continuidade na edição do mês de junho, p. 249-65.

39 SILVA, J. L. W. Isto é o... Op. cit., v. 1, p. 118.

40 Referimo-nos, aqui, às duas maiores facções políticas do Segundo Reinado, o Partido Conservador e o Partido Liberal. Destacamos que, em 1862, foi formada uma frente parlamentar de centro que ficou conhecida como Liga Progressista, englobando conservadores dissidentes e liberais, defendendo uma 
em razão dos seus estreitos laços com o ambiente palaciano e profunda identificação com a figura do imperador, seu defensor perpétuo, as feições conservadoras da SAIN mostravam-se mais evidentes. Com isso, a influência política da instituição podia variar de acordo com a conjuntura e a disposição de forças no bloco do poder. ${ }^{41}$ Já quanto ao fracasso da proposta de 1874, as poucas informações colhidas não nos permitem um juízo mais consolidado. Observamos somente que um novo projeto de lei visando à revisão da Lei de Patentes de 1830 seria lançado na Câmara dos Deputados em 1881, no contexto de um gabinete liberal. A SAIN não teve nenhuma participação nessa nova proposta.

\section{Patentes e interesses econômicos}

Na segunda metade do século XIX, a economia brasileira se submeteu a transformações significativas. A expansão capitalista proporcionou a espaços periféricos como o Brasil não apenas maior acesso a bens e serviços oriundos dos países centrais, como também a capitais e a novas tecnologias. A expansão da malha ferroviária, o desenvolvimento urbano, a elevação dos investimentos externos, além do avanço das atividades manufatureiras - a despeito do absoluto primado da agroexportação - são marcas indeléveis do período. Além disso, novos marcos jurídicos prestaram-se a proporcionar estímulos à modernização do ambiente econômico. ${ }^{42}$ Diante da constante elevação dos custos de produção - especialmente os relacionados à força de trabalho - e da necessidade de elevação da qualidade dos gêneros de exportação, tendo em vista a sua inserção em um mercado internacional em expansão, a mecanização da lavoura e a adoção de novos métodos de processamento apresentavam-se como soluções. Em suma, se até a primeira metade do século a agricultura, principal atividade econômica do país, pôde se expandir com base na superexploração do trabalho e dos recursos naturais, combinada à utilização de técnicas e recursos rudimentares, no contexto aqui analisado a tecnologia, antes secundária, passava a constituir um fator de produção relevante.

Uma vez que a estrutura produtiva local passava a incorporar paulatinamente os avanços tecnológicos que se desenvolviam no exterior, é compreensível que o sistema patentário ganhasse novas dimensão e funcionalidade. Se até então eram subutilizadas no país, na nova conjuntura as patentes, instrumentos que garantiam a propriedade sobre a tecnologia, passavam a ter seu uso alargado. Segundo levantamento efetuado por Ernesto

plataforma reformista, ainda que moderada. Transformada em partido em 1864, a Liga Progressista, no entanto, acabou se mostrando uma experiência efêmera, sendo dissolvida em 1868. Nova alteração na dinâmica de forças partidárias ocorreria no início dos anos 1870, com a fundação do Partido Republicano.

${ }^{41}$ Baseando-se em tal hipótese, não seria à toa que um dos períodos em que a instituição se mostrou mais ativa e influente ocorreu durante a situação conservadora de 1868-1878, em que sócios efetivos como o Visconde de Itaboraí, o Visconde de Rio Branco e o Marquês de São Vicente ocuparam o Conselho de Ministros. A percepção é corroborada pelo fato de a subsequente situação liberal (1878-1885) ter marcado justamente um declínio das atividades da SAIN.

42 Podemos citar como exemplos o Código Comercial (1850), Lei de Terras (1850), Lei Euzébio de Queiroz (1850), Lei Ferroviária (1852), reforma bancária (1853), Lei do Ventre Livre (1871), etc. 
Carrara Júnior e Hélio Meirelles, entre 1830 e 1850 foram concedidas no Brasil 68 patentes, incluindo-se as introduções. Já entre 1851 e 1871, foram concedidos 144 outros privilégios, um crescimento de cerca de $112 \%$. A elevação do número de concessões se acentua entre 1872 e 1881, interstício em que foram concedidas 547 patentes. ${ }^{43}$

Observando-se a natureza dos objetos patenteados, nota-se a sua concentração em três campos: beneficiamento agrícola (principalmente do café); máquinas e equipamentos aplicados a fábricas; meios de transporte. Nada de surpreendente, considerando-se o crescimento alcançado nos respectivos segmentos (cafeicultor, manufatureiro e ferroviário), principalmente a partir dos anos 1870. E quem eram esses patenteadores? Primeiramente, inventores e empresas estrangeiras, que desenvolviam novos bens e equipamentos em seus países de origem e pouco a pouco se aventuravam fora de suas fronteiras, vislumbrando no Brasil um mercado em crescimento. Somam-se a tal grupo os produtores estabelecidos no Brasil, nacionais ou estrangeiros aqui radicados. À medida que a economia se diversificava, a incorporação progressiva de novas tecnologias passava a se apresentar como um fator estratégico, permitindo a poupança de braços, engendrando ganhos de escala, elevando a qualidade dos gêneros e viabilizando o aproveitamento de oportunidades de mercado. ${ }^{44} \mathrm{Em}$ outros casos, as patentes também eram concebidas como ferramentas de negócio, aplicadas não no intuito de explorar um dado bem ou processo de produção, mas como meio para auferir renda com o recebimento de royalties. Por último, não se pode negligenciar a ação dos inventores eventuais ou diletantes, geralmente comerciantes, fabricantes e artífices de pequeno porte - ou mesmo simples curiosos - que no quotidiano de suas atividades desenvolviam objetos com baixo grau de complexidade, conferindo melhoria funcional a outros já existentes.

É na área de máquinas e equipamentos agrícolas que a ação dos patenteadores nacionais (e aqui nos referimos à residência, não à origem) mostrava-se mais frequente. Luiz Cláudio Moisés Ribeiro, em seu estudo sobre desenvolvimento técnico e patenteamento na área de beneficiamento de café, oferece-nos uma boa visão desse fenômeno. Segundo o autor, a necessidade de modernização da produção cafeeira gerou estímulos à inovação no setor, na medida em que nem sempre as soluções eram encontradas na tecnologia importada. Logo, a adaptação da maquinaria estrangeira às condições locais era ação comum entre esses fabricantes, por meio da modificação de peças e dispositivos. Nas palavras do autor:

Necessitando modernizar-se, a economia cafeeira foi buscar auxílio nos detentores de saber técnico aplicável às fainas da lavoura e às vicissitudes dos meios de transporte. Não era possível simplesmente alterar cirurgicamente o quadro estrutural importando inovações tecnológicas - como as locomotivas a vapor. Existia um espaço para a criatividade dentro de limites definidos. Desse

\footnotetext{
${ }^{43}$ CARRARA JÚNIOR, E.; MEIRELLES, H. A indústria Química e o desenvolvimento do Brasil - 1500-1889. São Paulo: Metalivros, 1996, v. 2, p. 873-906.

${ }^{44}$ Os impactos da Secessão estadunidense e os esforços da guerra contra o Paraguai são exemplos de oportunidades para a expansão do setor manufatureiro no Brasil, especialmente o têxtil e o de fundição.
} 
modo, o inventor encontrou no circuito da exportação uma franja para sua atuação. ${ }^{45}$

Ribeiro sustenta que a implementação da inovação na lavoura - esta progressivamente refletida em patentes - deu-se a partir de diferentes formas. Primeiramente, os próprios cafeicultores faziam-se inventores ou aperfeiçoadores de invenções, "como ocorreu com vários membros da família Arruda Botelho", ${ }^{46}$ estabelecidos na região de São Carlos, ou com os Souza Breves, do Vale do Paraíba fluminense. ${ }^{47}$ Havia produtores que patrocinavam experiências com maquinaria, tendo em vista a obtenção de melhores resultados na safra, e também aqueles que encomendavam novos equipamentos a "maquinistas", profissionais especializados na montagem e manutenção de instalações mecânicas. ${ }^{48}$ Ou ainda, os fazendeiros aproveitavam-se da oferta de máquinas e equipamentos gerada por agentes dedicados à atividade inventiva, empresários-inventores que procuravam explorar um campo em plena expansão (a cafeicultura) para obter lucros com a comercialização da tecnologia nele aplicada. ${ }^{49}$

Parte desses empresários-inventores estava firmemente instalada na SAIN. Alguns deles chegaram inclusive a participar das seções especializadas da entidade, encarregadas do exame prévio das patentes. Podemos citar o caso do norte-americano William van Vleck Lidgerwood, residente na região de Campinas desde 1861, fabricante de máquinas agrícolas e detentor de uma série de patentes por invenções e melhoramentos. ${ }^{50}$ Lidgerwood foi membro da Seção de Máquinas e Aparelhos, aquela a que era submetido o maior número de exames. Seus pedidos de patentes - todos deferidos - foram examinados, portanto, pela própria seção que integrava. Exemplo disso é a sua patente por melhoramento em máquina de descascar café, concedida em 31 de março de 1871. O parecer da Seção de Máquinas e Aparelhos, assinado por André Rebouças e Antônio de Paula Freitas, demais componentes da seção, não apenas foi favorável ao peticionário como também recomendou a concessão de recompensas mais significativas pelos esforços por ele despendidos na atividade tomada como mais importante da economia nacional. ${ }^{51}$ Obviamente, esse tipo de inserção em uma instância

\footnotetext{
${ }^{45}$ RIBEIRO, L. C. M. Ofício criador... Op. cit., 59.

${ }^{46}$ Ibidem, p. 60.

${ }^{47}$ Ibidem, p. 133. Uma patente concedida a J. L. de Souza Breves \& Cia., em 1874, para um processo de armazenamento de café pode ser encontrada no Arquivo Nacional do Rio de Janeiro (AN-RJ), Decretos do Executivo - Período Imperial (22), BR AN, RIO 22.0.0.2481.
}

${ }^{48}$ RIBEIRO, L. C. M. Ofício criador... Op. cit., p. 128-133.

49 Outra análise interessante sobre o desenvolvimento técnico da agricultura em São Paulo e a aplicação de novas máquinas à lavoura também pode ser encontrada em: CRIBELLI, T. Industrial Forests and Mechanical Marvels: Modernization in Nineteenth-Century Brazil. New York: Cambridge University Press, 2016.

50 Sobre a trajetória de William van Vleck Lidgerwood, ver: SABA, R. American Mirror: The United States and the Empire of Brazil in the Age of Emancipation. 2017. Thesis (Ph. D.) - University of Pennsylvania, Philadelphia.

${ }^{51}$ O Auxiliador, Rio de Janeiro, ano XXXVIII, n. 1, jan. 1871, p. 60-61. As demais patentes obtidas por Guilherme van Vleck Lidgerwood e sua empresa podem ser encontradas em: AN-RJ, Coleção Privilégios Industriais (PI). Alguns exemplos: Secador Lidgerwood (BR AN, RIO. PI 8940); moinho e secador universal de sal (BR AN, RIO. PI 9081); máquina aperfeiçoada para despolpar café (BR AN, RIO. PI 93); 
relevante dentro do processo de concessão de patentes (ainda que sem poder decisório) permitia uma constante atuação em defesa de interesses econômicos particulares. Inclusive se considerarmos o fato de que as patentes requeridas por eventuais concorrentes passavam por sua avaliação.

Encontramos exemplo análogo na experiência dos irmãos Henry e Charles Hargreaves, filhos de um inglês com uma portuguesa e proprietários de fábricas no Rio de Janeiro. ${ }^{52}$ Seus respectivos portfólios de patentes eram extensos, passando por aparelhos de refrigeração, fornos, caldeiras, fabricação de rolhas e máquinas para beneficiamento de café. ${ }^{53}$ Ambos eram sócios efetivos da SAIN, frequentando regularmente aquele espaço de sociabilidade. O mais velho, Henry Edward, chegou a ocupar o cargo de secretário da entidade e tomar assento na Seção de Máquinas e Aparelhos ao final da década de 1870. Nesta mesma época, requereu, em parceria com o engenheiro André Rebouças - conforme já mencionado, outro membro da mesma seção - , privilégio de 20 anos para instalação de uma "fábrica destinada a relaminar, acierar e restaurar o ferro". ${ }^{54}$ Luiz Goffredo Escragnolle Taunay, que também era membro do Instituto Politécnico Brasileiro, é outro nome a ser destacado. Detentor de diversas patentes, também integrou a Seção de Máquinas e Equipamentos, substituindo Henry Hargreaves a partir da década de $1880 .^{55}$ Enfim, é considerável o número de atores envolvidos no desenvolvimento de máquinas e equipamentos agrícolas a partir do terceiro quartel do século, e a utilização do sistema de patentes por esse grupo tornou-se cada vez mais comum. Ser sócio efetivo da SAIN e participar de suas sessões especializadas, em tais casos, apresentavase como uma oportunidade interessante para a defesa de seus interesses e alcance de benefícios econômicos.

Notemos, enfim, que no terceiro quartel do século a questão da modernização da estrutura produtiva, por meio da incorporação dos novos recursos tecnológicos que surgiam nos "países civilizados", já estava lançada ao centro da agenda econômica nacional. A SAIN, por suas natureza e missão, destaca-se nesse contexto, tomando parte no processo de concessões de exclusivos a inventores e constituindo um espaço privilegiado de debate e reflexão sobre esse tipo de temática. Decerto não era o único. O papel desempenhado por outras instituições científico-educacionais, como a Escola Politécnica e os institutos agrícolas, não pode em nenhuma hipótese ser desprezado, tendo já sido alvo da atenção de alguns

ventilador-apartador duplo de café (BR AN, RIO. PI 99); Chapa Lidgerwood para descascar café (BR AN, RIO. PI 423); métodos e aparelhos aperfeiçoados aplicáveis à dessecação do café (BR AN, RIO. PI 1223).

52 SILVA, op. cit., v. 2, p. 59-61.

${ }^{53}$ ANRJ, Coleção Privilégios Industriais (PI). Alguns exemplos: processo e maquinismo para conservação de alimentos (BR AN, RIO. PI 182); novo sistema de fornos (BR AN, RIO. PI 233); sistema de caldeiras (BR AN, RIO. PI 234); máquina de beneficiar café Hargreaves (BR AN, RIO. PI 403).

${ }^{54}$ SILVA, op. cit., v. 2, p. 60.

${ }^{55}$ RIBEIRO, L. C. M. Ofício criador... Op. cit., p. 131. Entre os mais importantes exemplos de patentes concedidas a Luiz Goffredo Escragnolle Taunay está a referente a uma máquina de secar café (BR AN, RIO. PI 8.219), que acabou gerando outras patentes em razão de seus melhoramentos (BR AN, RIO. PI 6819; BR AN, RIO. PI 7470; BR AN, RIO. PI 9136; etc.). 
pesquisadores. ${ }^{56} \mathrm{~A}$ despeito de tais influências, é seguro afirmar que, especialmente no que se refere à discussão sobre a propriedade tecnológica, nenhuma outra instituição - ou ator social isolado - teve um papel tão destacado quanto a SAIN. Coube a seu corpo de sócios, especialmente nos três decênios que se seguiram à extinção da Junta do Comércio, o levantamento e identificação de gargalos burocráticos, ações sistemáticas em prol da adequação da legislação às transformações econômicas em curso e a proposição de medidas concretas visando ao aperfeiçoamento da estrutura institucional então existente. Obviamente, não dispunha a entidade de competência formal ou recursos de poder para concretizar as intervenções tomadas como necessárias. Mas teve participação fundamental, no âmbito da sociedade civil, na promoção da circulação de ideias, formação de massa crítica e defesa de uma reforma do sistema patentário brasileiro.

\section{Considerações finais}

A Auxiliadora constituiu, desde a sua fundação, um espaço frequentado por importantes personagens da elite imperial, sendo tomada, nos termos do discurso da época, como uma das mais ilustres associações do Império, conferindo status e prestígio a seus membros. ${ }^{57}$ Conforme atestava em 1837 o Primeiro Secretário da instituição, Raimundo José de Cunha Mattos, seus quadros eram formados por "Conselheiros de Estado, Ministros e Secretários de Estado, Senadores, Deputados, Titulares, Eclesiásticos, Ministros e Empregados de Tribunais, Médicos, Advogados, Negociantes, Capitalistas, Lavradores ou Agricultores, Proprietários, Artífices, e Generais", ${ }^{58}$ em suma, as figuras "mais respeitáveis" da sociedade. Decerto, como afirmam Heloísa Domingues e Priscila Barreto, a SAIN prestou uma colaboração importantíssima ao processo de institucionalização das ciências no Brasil, promovendo a introdução e divulgação de práticas e saberes científicos. Mas não somente isso. Entendemos que, para além de uma natureza exclusivamente científica, alicerçada em um ideário ilustrado, a instituição constituía um espaço de construção e reiteração dos valores e representações que sustentavam a ordem imperial, apresentando-se como "a instituição mais representativa da correlação de forças sociais que moldou o bloco histórico do Império, dos anos cinquenta aos anos setenta do século XIX". ${ }^{59}$ Como entidade da sociedade civil, atuou nas dimensões política, econômica, técnica e ideológica em defesa do desenvolvimento da lavoura, concorrendo para a afirmação e a primazia de um projeto agrarista. Uma das mais importantes funções cumpridas pela intelectualidade que a compunha era a ratificação de uma imediata identificação dos interesses de uma determinada fração de classe - no caso, a dos proprietários rurais - com

\footnotetext{
${ }^{56}$ Ver, por exemplo, HEIZER, A.; VIDEIRA, A.A.P. (orgs.). Ciência, civilização e império nos trópicos. Rio de Janeiro: Access, 2001.

57 SILVA, J. L. W. Isto é o... Op. cit., v. 1, p. 86-87.

${ }^{58}$ O Auxiliador, Rio de Janeiro, ano V, n. 9, set. 1837, p. 267-285. A citação se encontra na p. 269.

${ }^{59}$ SILVA, J. L. W. Isto é o... Op. cit., v. 2, p. 160.
} 
os de toda a sociedade, impondo-os como "interesses nacionais". Sob o ponto de vista simbólico, o discurso e as ações da SAIN legitimavam a ideia de que o progresso do setor agroexportador representava o progresso da própria Nação.

A eleição da agricultura como mola propulsora da economia, para a qual se deveria voltar o grosso dos investimentos privados e dos suportes governamentais, pressupunha, no entanto, a sua contínua evolução. O desenvolvimento da lavoura demandava a racionalização do processo produtivo, o que passava pela incorporação constante de novos recursos e técnicas. ${ }^{60}$ Essa era uma função fulcral dos intelectuais encastelados na SAIN: articular a organização e o atendimento dos interesses dos produtores rurais, grupo social que exercia a supremacia dentro da ordem imperial. Em termos gramscianos, podemos concebê-la como um aparelho privado de hegemonia, uma instituição voltada à construção do consenso que permite a uma fração de classe se fazer dirigente das demais, impondo seus valores, representações e visões de mundo. ${ }^{61}$

A SAIN envidou constantes esforços visando à elevação da produtividade, redução de custos e a melhoria da qualidade dos gêneros nacionais, fomentando a aplicação do conhecimento científico à produção, a mecanização das atividades econômicas e a disseminação do conhecimento técnico entre os agentes produtivos. Em seu seio, as patentes eram concebidas como ferramentas de incentivo à inovação e de facilitação do acesso dos produtores à tecnologia disponível nas principais potências ocidentais. Atuou a Auxiliadora como parte do processo de concessão de exclusivos a inventores - exercendo uma função consultiva - e na formulação de propostas para o aprimoramento da legislação patentária, tendo em vista sua adequação aos padrões internacionais. Notamos nessa empresa uma reiterada defesa da desburocratização de procedimentos e da expansão das prerrogativas dos inventores, isto é, o reforço e o alargamento dos direitos de propriedade sobre a tecnologia. Esse tipo de ação mostrava-se benéfico aos interesses dos proprietários rurais e dos empresários-inventores, muitos deles sócios da SAIN e membros de suas seções especializadas.

Ao fim dos anos 1870, a SAIN atingia o ápice de seu prestígio e influência, chegando a contar com cerca de 2.000 sócios. ${ }^{62}$ As décadas que se seguiram, contudo, foram marcadas por um brusco declínio. A escassez de verbas provocada pela redução (e depois a extinção)

\footnotetext{
${ }^{60}$ SILVA, J. L. W. Isto é o... Op. cit., v. 2, p. 75.

${ }^{61} \mathrm{O}$ conceito de "Estado ampliado", proposto por Antonio Gramsci, estabelece uma unidade dialética entre sociedade política e sociedade civil, esferas tomadas como inextrincáveis, distintas teoricamente, porém unidas na prática social. A sociedade política, composta pelos aparelhos oficiais de poder, seria a dimensão de aplicação de uma ação político-coercitiva, garantindo o funcionamento de uma estrutura de dominação. A sociedade civil, por sua vez, seria a dimensão onde se desenvolvem as ações voluntárias e relações privadas entre os indivíduos, seus interesses, cultura e valores. É a partir deste lugar que a concepção de mundo de um grupo social impõe-se às dos demais, construindo-se uma hegemonia, isto é, o consenso ativo e sistemático que funda uma dada direção moral e ideológica. Sobre o assunto, ver: GRAMSCI, A. Maquiavel, a Política e o Estado Moderno. Rio de Janeiro: Civilização Brasileira, 1978; COUTINHO, C. N. Gramsci: um estudo sobre seu pensamento político. $2^{\mathrm{a}}$ ed. Rio de Janeiro: Civilização Brasileira, 2003.
}

${ }^{62}$ BARRETO, P. R. C. Sociedade Auxiliadora da... Op. cit., p. 400. 
das subvenções governamentais e a crescente evasão de sócios levou ao colapso de suas atividades, suscitando o fechamento das escolas profissionais noturnas, a interdição de sua biblioteca e a suspensão da publicação d'O Auxiliador. Inúmeras são as razões apontadas para o ocaso da instituição, embora por ora optemos por não enfrentar essa discussão. ${ }^{63}$ No que concerne ao campo das patentes, notamos que uma nova legislação promulgada em 1882 aboliu o exame prévio, mantendo-o apenas para os casos de produtos alimentícios, químicos e farmacêuticos. ${ }^{64}$ Só esse fato já contribuía em muito para o esvaziamento das funções consultivas prestadas pela SAIN ao governo. Além disso, a própria legislação estabelecia as autoridades e instâncias que deveriam se pronunciar nos casos em que os exames se fizessem necessários, excluindo desse rol a Auxiliadora. ${ }^{65}$ Curiosamente, um dos relatores do projeto de lei no Senado e autor do regulamento da Lei de Patentes de 1882, Diogo Velho Cavalcanti de Albuquerque, era sócio efetivo da SAIN.

A exclusão da SAIN do processo de análise dos pedidos de patentes repercutiria de maneira extremamente negativa entre os sócios da instituição. Em carta assinada por seu então presidente, Nicolau Joaquim Moreira, em janeiro de 1883, protestos veementes foram efetuados: "Bela recompensa para cinquenta anos de tão valiosos serviços!". ${ }^{66}$ Esparsas consultas chegaram à entidade a partir de então, nos casos excepcionais em que o governo recorreu a peritos para aferição de erros no processo de concessão. ${ }^{67} \mathrm{Com}$ a reforma dos estatutos em 1891, as seções especializadas deixaram de existir, levando ao encerramento definitivo da função consultiva prestada pela SAIN. Definitivamente, a nova ordem em construção não reservava espaço para a velha Auxiliadora.

\footnotetext{
63 Por extrapolar os limites e objetivos deste artigo, deixaremos para discutir a crise da SAIN em oportunidade futura. Sobre o assunto, ver: SILVA, J. L. W. Isto é o... Op. cit., v. 1, p. 203-229; BARRETO, P. R. C. Sociedade Auxiliadora da... Op. cit., p. 404-408.

64 Lei n.o 3.129, de 14 de outubro de 1882.

65 O Decreto n. ${ }^{\circ} 8.820$, de 30 de dezembro de 1882, estabeleceu o regulamento da Lei de Patentes de 1882, identificando como autoridades ou instâncias competentes para a execução do exame prévio o Procurador da Coroa, Soberania e Fazenda Nacional (caso a invenção parecesse contrária à lei, moral ou segurança pública), a Junta Central de Higiene Pública, a Escola Politécnica, as academias militares, a Faculdade de Medicina da Corte ou quaisquer outras repartições públicas especializadas.

66 O Auxiliador, Rio de Janeiro, ano LI, n. 1, jan. 1883, p. 2.

${ }^{67}$ Conforme previsto no artigo 44 do Decreto n. ${ }^{\circ} 8.820$.
} 


\section{Referências}

\section{Fontes}

ARQUIVO NACIONAL - RIO DE JANEIRO. Fundo Decretos do Executivo - Período Imperial (BN ANRIO 22). Coleção Privilégios Industriais (BN ANRIO PI)

BIBLIOTECA NACIONAL - RIO DE JANEIRO. Hemeroteca Digital. O auxiliador da indústria nacional. Rio de Janeiro: Sociedade Auxiliadora da Indústria Nacional, 1833-1896.

BRASIL. Câmara dos Deputados. Anais do Parlamento Brasileiro. Câmara dos Srs. Deputados. Primeiro ano. da décima quarta legislatura. Sessão de 1869. Tomo 5. Rio de Janeiro: Typographia Imperial e Constitucional de J. Villeneuve \& Co., 1869.

BRASIL. Decreto n. ${ }^{\circ} 2.748$, de 16 de fevereiro de 1861. Organiza a Secretaria dos Negócios da Agricultura, Comércio e Obras Públicas. Coleção de Leis do Império do Brasil, tomo XXIV, parte II. Rio de Janeiro: Typographia Nacional, 1861, p. 129-41. Disponível em https://www2.camara.leg.br/atividade-legislativa/legislacao/doimperio/colecao6.html. Acesso em 12 ago. 2019.

BRASIL. Decreto n. ${ }^{\circ} 4.333$, de 12 de fevereiro de 1869. Aprova a reforma dos estatutos da Sociedade Auxiliadora da Indústria Nacional. Coleção de Leis do Império do Brasil, tomo XXXII, parte II. Rio de Janeiro: Typographia Nacional, 1869, p. 40-7. Disponível em https://www2.camara.leg.br/atividade-legislativa/legislacao/doimperio/colecao6.html. Acesso em: 12 ago. 2019.

BRASIL. Decreto n. ${ }^{\circ} 8.820$, de 30 de dezembro de 1882. Aprova o regulamento para execução da Lei n.03.129, de 14 de outubro de 1882. Coleção das Leis do Império do Brasil de 1882. Parte II. Tomo XLV. v. II. Rio de Janeiro: Typographia Nacional, 1883, p. 636-57. Disponível em https://www2.camara.leg.br/atividade-legislativa/legislacao/doimperio/colecao8.html. Acesso em: 30 ago. 2019.

BRASIL. Lei de 28 de agosto de 1830. Concede privilégio ao que descobrir, inventar ou melhorar uma indústria útil e um prêmio ao que introduzir uma indústria estrangeira, e regula a sua concessão. Coleção das Leis do Império do Brasil de 1882. Parte I. Rio de Janeiro: Typographia Nacional, 1876, p. 20-3. Disponível em https://www2.camara.leg.br/atividadelegislativa/legislacao/doimperio/colecao2.html. Acesso em: 30 ago. 2019.

BRASIL. Lei n. ${ }^{0} 3.129$, de 14 de outubro de 1882. Regula a concessão de patentes aos autores de invenção ou descoberta industrial. Coleção das Leis do Império do Brasil de 1882. Parte I. Tomo XXIX. V. 1. Rio de Janeiro. Typographia Nacional, 1882, p. 81-7. Disponível em https://www2.camara.leg.br/atividade-legislativa/legislacao/doimperio/colecao8.html. Acesso em 30 ago. 2019.

ESTATUTOS da Sociedade Auxiliadora da Indústria Nacional, novamente organisados em conformidade da provisão de 31 de outubro de 1825, e do aviso de 5 de agosto de 1831 . Rio de Janeiro: Typographia Austral, 1838.

ESTATUTOS da Sociedade Auxiliadora da Indústria Nacional. Rio de Janeiro: Typographia Imperial, 1828.

\section{Bibliografia}


BARRETO, P. R. C. Sociedade Auxiliadora da Indústria Nacional: o templo carioca de Palas Atena. 2009. Tese (Doutorado em História das Ciências e das Técnicas e Epistemologia) Universidade Federal do Rio de Janeiro, Rio de Janeiro. Disponível em: http://www.dominiopublico.gov.br/pesquisa/DetalheObraForm.do?select_action=\&co_obra $=17$ 0501. Acesso em: 25 jul. 2019.

BLAKE, A. V. S. Diccionario Bibliographico Brazileiro. Vol. 3. Rio de Janeiro: Imprensa Nacional, 1895.

CARONE, E. O Centro Industrial do Rio de Janeiro e sua importante participação na economia nacional (1827-1977). Rio de Janeiro: CIRJ; Cátedra, 1978.

CARRARA JÚNIOR, E.; MEIRELLES, H. A indústria Química e o desenvolvimento do Brasil 1500-1889. São Paulo: Metalivros, 1996. 2 vols.

CARVALHO, J. M. A construção da ordem: a elite imperial. Teatro das sombras: a política imperial. $3^{a}$ ed. Rio de Janeiro: Civilização Brasileira, 2007.

COUTINHO, C. N. Gramsci: um estudo sobre seu pensamento político. $2^{\mathrm{a}}$ ed. Rio de Janeiro: Civilização Brasileira, 2003.

CRIBELLI, T. Industrial Forests and Mechanical Marvels: Modernization in Nineteenth-Century Brazil. New York: Cambridge University Press, 2016.

DOMINGUES, H. M. B. A Sociedade Auxiliadora da Indústria Nacional e as Ciências Naturais no Brasil Império. In: DANTES, M. A. M. (org.) Espaços da Ciência no Brasil: 1800-1930. Rio de Janeiro: Ed. Fiocruz, 2001.

GRAMSCI, A. Maquiavel, a Política e o Estado Moderno. Rio de Janeiro: Civilização Brasileira, 1978.

HEIZER, A.; VIDEIRA, A. A. P. (orgs.). Ciência, civilização e império nos trópicos. Rio de Janeiro: Access, 2001.

MALAVOTA, L. M. A construção do sistema de patentes no Brasil: um olhar histórico. Rio de Janeiro: Lumen Juris, 2011.

PERUGINE, E. Palavra indústria na revista O Auxiliador da Indústria Nacional: 1833-1843. 1978. Dissertação (Mestrado em História Social) - Faculdade de Filosofia, Letras e Ciências Humanas, Universidade de São Paulo, São Paulo.

RIBEIRO, L. C. M. Ofício criador: invento e patente de máquina de beneficiar café no Brasil (1870-1910). 1995. Dissertação (Mestrado em História) - Faculdade de Filosofia, Letras e Ciências Humanas, Universidade de São Paulo, São Paulo.

SABA, R. American Mirror: The United States and the Empire of Brazil in the Age of Emancipation. 2017. Thesis (Ph. D.) - University of Pennsylvania, Philadelphia. Disponível em: https://repository.upenn.edu/cgi/viewcontent.cgi?article=4347\&context=edissertations.

Acesso em: 07 dez. 2019.

SILVA, J. L. W. Isto é o que me parece: a Sociedade Auxiliadora da Indústria Nacional (18271904) na formação social brasileira. 1979. Dissertação (Mestrado em História) - Instituto de Ciências Humanas e Filosofia, Universidade Federal Fluminense, Niterói (RJ). 2 vols.

VANUCCI, J. C. P. As invenções técnicas brasileiras no Segundo Reinado. Estudo das Comissões Técnicas da Sociedade Auxiliadora da Indústria Nacional nas concessões de privilégios de patentes entre 1833 e 1862. 2016. Tese (Doutorado em História da Ciência) Pontifícia Universidade Católica, São Paulo. Disponível em: http://leto.pucsp.br/bitstream/hancle/19257/2/Jo\%C3\%A30\%20Carlos\%Piedade\%20Vanucci. pdf. Acesso em: 7 dez. 2019. 